\title{
The reaction between silylene and ammonia: some gas-phase kinetic and quantum chemical studies
}

Article

Accepted Version

Becerra, R., Cannady, J. P. and Walsh, R. (2007) The reaction between silylene and ammonia: some gas-phase kinetic and quantum chemical studies. Silicon Chemistry, 3 (3-4). pp. 131138. ISSN 1572-8994 doi: https://doi.org/10.1007/s11201-0069018-3 Available at https://centaur.reading.ac.uk/32066/

It is advisable to refer to the publisher's version if you intend to cite from the work. See Guidance on citing.

To link to this article DOI: http://dx.doi.org/10.1007/s11201-006-9018-3

Publisher: Springer

All outputs in CentAUR are protected by Intellectual Property Rights law, including copyright law. Copyright and IPR is retained by the creators or other copyright holders. Terms and conditions for use of this material are defined in the End User Agreement.

www.reading.ac.uk/centaur 
Central Archive at the University of Reading

Reading's research outputs online 


\title{
The reaction between silylene and ammonia: some gas-phase kinetic and quantum chemical studies.
}

\author{
Rosa Becerra ${ }^{1}$, J. Pat Cannady ${ }^{2} \&$ Robin Walsh ${ }^{3, *}$ \\ ${ }^{1}$ Instituto de Quimica-Fisica 'Rocasolano', C.S.I.C., C/Serrano 119, 28006 Madrid, Spain \\ ${ }^{2}$ Dow Corning Corporation, P.O. Box 995, Mail Stop CO1232, Midland, Michigan, 48686-0995 \\ ${ }^{3}$ Department of Chemistry, University of Reading, Whiteknights, P.O. Box 224, Reading, RG6 \\ 6AD, UK.*Author for correspondence (e-mail: r.walsh@reading.ac.uk)
}

\section{Abstract}

Time-resolved kinetic studies of the reaction of silylene, $\mathrm{SiH}_{2}$, generated by $193 \mathrm{~nm}$ laser flash photolysis of silacyclopent-3-ene, have been carried out in the presence of ammonia, $\mathrm{NH}_{3}$. Second order kinetics were observed. The reaction was studied in the gas phase at 10 Torr total pressure in $\mathrm{SF}_{6}$ bath gas at each of the three temperatures, 299, 340 and $400 \mathrm{~K}$. The second order rate constants (laser pulse energy of $60 \mathrm{~mJ} /$ pulse) fitted the Arrhenius equation:

$$
\log \left(k / \mathrm{cm}^{3} \text { molecule } \mathrm{s}^{-1}\right)=(-10.37 \pm 0.17)+\left(0.36 \pm 1.12 \mathrm{~kJ} \mathrm{~mol}^{-1}\right) / R T \ln 10
$$

Experiments at other pressures showed that these rate constants were unaffected by pressure in the range 10-100 Torr, but showed small decreases in value at 3 and 1 Torr. There was also a weak intensity dependence, with rate constants decreasing at laser pulse energies of $30 \mathrm{~mJ} / \mathrm{pulse}$. $\mathrm{Ab}$ initio calculations at the $\mathrm{G} 3$ level of theory, show that $\mathrm{SiH}_{2}+\mathrm{NH}_{3}$ should form an initial adduct (donor-acceptor complex), but that energy barriers are too great for further reaction of the adduct. This implies that $\mathrm{SiH}_{2}+\mathrm{NH}_{3}$ should be a pressure dependent association reaction. The experimental data are inconsistent with this and we conclude that $\mathrm{SiH}_{2}$ decays are better explained by reaction of $\mathrm{SiH}_{2}$ with the amino radical, $\mathrm{NH}_{2}$, formed by photodissociation of $\mathrm{NH}_{3}$ at $193 \mathrm{~nm}$. The mechanism of this previously unstudied reaction is discussed. 


\section{Introduction}

Silylenes are of importance because they are implicated in the thermal and photochemical breakdown mechanisms of silicon hydrides and organosilanes, as well as being key intermediates in CVD. Time resolved kinetic studies, carried out in recent years, have shown that the simplest silylene, $\mathrm{SiH}_{2}$, reacts rapidly and efficiently with many chemical species. ${ }^{1,2}$ Examples of its reactions include $\mathrm{Si}-\mathrm{H}$ bond insertions, $\mathrm{C}=\mathrm{C}$ and $\mathrm{C} \equiv \mathrm{C} \pi$-bond additions. ${ }^{3} \mathrm{SiH}_{2}$ also has a great affinity for electronegative elements and will react with lone pair donor species containing the elements of $\mathrm{N}, \mathrm{O}, \mathrm{F}, \mathrm{P}, \mathrm{S}$ and $\mathrm{Cl}$ amongst others ${ }^{4}$. We, and others, have recently studied the kinetics of its reactions with "O-donor" molecules, $\mathrm{H}_{2} \mathrm{O}^{5,6}, \mathrm{CH}_{3} \mathrm{OH}\left(\mathrm{CD}_{3} \mathrm{OD}\right)^{5}, \mathrm{Me}_{2} \mathrm{O}^{7,8}$, $\mathrm{Me}_{2} \mathrm{CO}^{9}, \mathrm{MeCHO}^{10,11}, \mathrm{CO}^{12}, \mathrm{CO}_{2}{ }^{13}$ and $\mathrm{O}_{2}{ }^{14}$ itself, and also with "Cl-donor" molecules, $\mathrm{HCl}^{15}$ and $\mathrm{CH}_{3} \mathrm{Cl}^{16}$. We have also previously reported kinetic studies of the reactions of $\mathrm{SiH}_{2}$ with the $\mathrm{N}$-containing molecules $\mathrm{N}_{2} \mathrm{O}^{17}, \mathrm{NO}^{18}$ and even $\mathrm{N}_{2}{ }^{19}$ (although no reaction was found in this case). None of these can be represented as typical reactions of a silylene with the nitrogen lone pair. We therefore set out to investigate the prototype reaction of $\mathrm{SiH}_{2}$ with $\mathrm{NH}_{3}$. This reaction has the added importance in that it may be considered as a model for some of the likely reaction steps involved in producing solid materials such as $\mathrm{Si}_{3} \mathrm{~N}_{4}{ }^{20}$.

There is no previous experimental study of this reaction. At the outset of this work we were aware of the potential problem of substrate absorption at the UV photolysis wavelength (193nm) required for generation of $\mathrm{SiH}_{2}$ from our precursor (silacyclopent-3-ene). $\mathrm{NH}_{3}$ has an absorption band $\left(\tilde{A}^{1} \mathrm{~A}_{2}{ }^{\prime \prime} \leftarrow \tilde{X}^{1} \mathrm{~A}_{1}\right)$ in the wavelength region $170-217 \mathrm{~nm}^{21}$. Whether this would give rise to kinetic complications was not predictable in the absence of knowledge of the rate constants for the reaction under consideration. We therefore decided to press ahead with the study and evaluate the findings. Earlier theoretical work by Raghavachari et $\mathrm{al}^{4}$ gives some guidance as to what to expect. Calculations at the MP4 level with allowance for electron correlation effects, indicate a mechanism involving initial formation of a donor acceptor adduct 
followed by rearrangement by 1,2 H-migration to give the formal insertion product, silylamine, viz:

$$
\mathrm{SiH}_{2}+\mathrm{NH}_{3}=\mathrm{H}_{2} \mathrm{Si} \cdot \mathrm{NH}_{3} \rightarrow \mathrm{H}_{3} \mathrm{SiNH}_{2}
$$

The donor acceptor complex was bound by some $105 \mathrm{~kJ} \mathrm{~mol}^{-1}$ and the rearrangement barrier calculated to be ca $54 \mathrm{~kJ} \mathrm{~mol}^{-1}$ above the reactant energy ${ }^{4}$. By analogy with findings for $\mathrm{SiH}_{2}+$ $\mathrm{H}_{2} \mathrm{O}^{5,6}$ which has a similar reaction mechanism (and calculated potential energy surface) this suggests that the $\mathrm{H}_{2} \mathrm{Si} \cdot \cdot \mathrm{NH}_{3}$ adduct will be the effective final product under experimental conditions (short timescale/moderate temperatures) because the rearrangement barrier for $\mathrm{H}_{2} \mathrm{Si} \cdot \mathrm{NH}_{3}$ to $\mathrm{H}_{3} \mathrm{SiNH}_{2}$ is too high. Stable donor acceptor adducts of silylenes with N-type lone pair donors have been detected in low temperature matrices ${ }^{22,23}$. The expectation here is therefore of an association reaction, which should require third body assistance to stabilise the initially formed vibrationally excited adduct. This implies pressure dependent second order kinetics. We describe here the results of an attempted experimental kinetic study, together with further theoretical calculations aimed at refining the energy surface of this reaction.

\section{Experimental Section}

Equipment, Chemicals and Method. The apparatus and equipment for these studies have been described in detail previously ${ }^{24,25}$. Only essential and brief details are therefore included here. $\mathrm{SiH}_{2}$ was produced by the $193 \mathrm{~nm}$ flash photolysis of silacyclopent-3-ene (SCP) using a Coherent Compex 100 exciplex laser. Photolysis pulses (beam cross section $4 \mathrm{~cm} \times 1$ $\mathrm{cm})$ were fired into a variable temperature quartz reaction vessel with demountable windows, at right angles to its main axis. $\mathrm{SiH}_{2}$ concentrations were monitored in real time by means of a Coherent 699-21 single-mode dye laser pumped by an Innova 90-5 argon ion laser and operating with Rhodamine 6G. The monitoring laser beam was multipassed 36 times along the vessel axis, through the reaction zone, to give an effective path length of $1.5 \mathrm{~m}$. A portion of the monitoring 
beam was split off before entering the vessel for reference purposes. The monitoring laser was tuned to $17259.50 \mathrm{~cm}^{-1}$, corresponding to the known ${ }^{\mathrm{R}} Q_{0, \mathrm{~J}}(5)$ strong rotation transition ${ }^{24,26}$ in the $\mathrm{SiH}_{2} \tilde{A}^{1} \mathrm{~B}_{1}(0,2,0) \leftarrow \tilde{X}^{1} \mathrm{~A}_{1}(0,0,0)$ vibronic absorption band. Light signals were measured by a dual photodiode/differential amplifier combination and signal decays were stored in a transient recorder (Datalab DL910) interfaced to a BBC microcomputer. This was used to average the decays of between 3 and 15 photolysis laser shots (at a repetition rate of 0.5 or $1 \mathrm{~Hz}$ ). The averaged decay traces were processed by fitting the data to an exponential form using a nonlinear least squares package. This analysis provided the values for first-order rate coefficients, $k_{\mathrm{obs}}$, for removal of $\mathrm{SiH}_{2}$ in the presence of known partial pressures of substrate gas.

Gas mixtures for photolysis were made up, containing between 3.1 and 4.2 mTorr of precursor $(\mathrm{SCP})$, variable pressures of $\mathrm{NH}_{3}$ between 30 and 300 mTorr, and inert diluent, $\mathrm{SF}_{6}$, up to total pressures between 1 and 100 Torr (although mainly 10 Torr $^{\dagger}$ ). Pressures were measured by capacitance manometers (Chell, Barocel). All gases used in this work were frozen and rigorously pumped to remove any residual air prior to use. SCP was a gift from the group of Professors Nefedov and Egorov. After redistillation, GC analysis showed it was $>85 \%$ pure. $\mathrm{NH}_{3}$ $\left(99.98 \%\right.$ ) was from BOC. Sulfur hexafluoride, $\mathrm{SF}_{6}$, (no GC-detectable impurities) was from Cambrian Gases. GC purity checks were carried out with a $3 \mathrm{~m}$ silicone oil column (OV101) operated at $60^{\circ} \mathrm{C} . \mathrm{N}_{2}$ was used as carrier gas and detection was by FID. Detection limits for hydrocarbon impurity peaks were better than $0.1 \%$ of the principal component.

Ab Initio Calculations. The electronic structure calculations were performed with the Gaussian 98 software package ${ }^{27}$. All structures were determined by energy minimization at the MP2=Full/6-31G(d) level. Transition State structures were characterised as first order saddle points by calculation of the hessian matrix. Stable structures, corresponding to energy minima, were identified by possessing no negative eigenvalues of the Hessian, whilst transition states

\footnotetext{
${ }^{\dagger} 1$ Torr $=133.3 \mathrm{Nm}^{-2}$
} 
were identified by having one and only one negative eigenvalue. The standard Gaussian-3 (G3) compound method ${ }^{28}$ was employed to determine final energies for all local minima. For transition states the elements of the G3 method were used, viz: optimization to TS at HF/631G(d), frequencies at HF/6-31G(d), optimization to TS at MP2=full/6-31G(d), followed by four single point energy determinations at the MP2=full/6-31G(d) geometry, viz: $\mathrm{QCISD}(\mathrm{T}) / 6-$ 31G(d), MP4/6-31+G(d), MP4/6-31G(2df,p), and MP2=full/G3large, and the values were combined according to the G3 procedure. ${ }^{28}$ The identities of the transition state structures were verified by calculation of Intrinsic Reaction Co-ordinates ${ }^{29}$ (IRC) at the MP2=Full/6-31G(d) or B3LYP/6-31G(d) levels. Reaction barriers were calculated as differences in G3 enthalpies at 298.15 K. In addition to these calculations, two further calculations were carried out at the MP2=full/6-31G(d,p) and MP2=full/6-311++G(2d,2p) levels in order to test the effects of larger basis sets.

\section{Results}

Preliminary Experiments. The gas phase UV spectrum of $\mathrm{NH}_{3}$ was recorded over the wavelength range, $190-220 \mathrm{~nm}$. The characteristic vibrational progression of the $\tilde{A} \leftarrow \tilde{X}$ system was observed $^{21}$ and the decadic extinction coefficient at $193 \mathrm{~nm}$ was calculated to be 985 $\mathrm{dm}^{3} \mathrm{~mol}^{-1} \mathrm{~cm}^{-1}$ in reasonable agreement with the literature ${ }^{21}$. At the partial pressures of $\mathrm{NH}_{3}$ employed in these experiments this means that up to $10 \%$ of the $193 \mathrm{~nm}$ laser pulse is absorbed by the substrate. SCP has a non-structured UV spectrum in this region with increasing absorbance at shorter wavelengths; the extinction coefficient at $193 \mathrm{~nm}$ is $967 \mathrm{dm}^{3} \mathrm{~mol}^{-1} \mathrm{~cm}^{-1}$. Because the partial pressures of SCP are much lower, the fractional light absorption is much less. Although photodecomposition of $\mathrm{NH}_{3}$ is known to occur (see discussion) at $193 \mathrm{~nm}$, blank experiments at the $\mathrm{SiH}_{2}$ detection wavelength (ca $579 \mathrm{~nm}$ ), showed no detectable transient absorption from $\mathrm{NH}_{3}$ photolysis alone. 
Kinetics. Preliminary experiments established that, for a given reaction mixture, decomposition decay constants, $k_{\mathrm{obs}}$, were not dependent on the exciplex laser energy within the normal routine range of variation $(50-70 \mathrm{~mJ} /$ pulse). However there was some systematic variation at lower pulse energies (see below). There was no dependence on the number of photolysis laser shots (up to 15 shots). The constancy of $k_{\text {obs }}$ ( 3 shot averages) showed that there was no effective depletion of reactants. Higher pressures of precursor were required at the higher temperatures because signal intensities decreased with increasing temperature. However, for the purposes of rate constant measurement at a given temperature the precursor pressure was kept fixed. At each temperature of study, a series of experiments was carried out to investigate the dependence of $k_{\mathrm{obs}}$ on $\mathrm{NH}_{3}$ pressure. The results of these experiments are shown in Figures 1 and 2. Reasonable linear fits were obtained, as expected for second order kinetics, although it should be noted that there is slightly higher scatter than is usually obtained in this kind of study ${ }^{5-18}$. Because the rate constants showed a dependence on laser pulse energy, two plots are shown, one for higher pulse energies (60 mJ) and one for lower values (ca $30 \mathrm{~mJ})$. Similar plots (not shown) were obtained for data recorded at $400 \mathrm{~K}$. The second order rate constants derived from the gradients of these plots by least squares fitting, are shown in Table 1. The error limits (precision) are single standard deviations. It can be seen that, for a given laser pulse energy, the rate constants are the same at each temperature within experimental error, although a small variation with temperature cannot be ruled out. Because the scatter of data increased with temperature, further experiments at higher temperatures were not carried out. An Arrhenius plot of the rate constants (at laser energies of $60 \mathrm{~mJ} /$ pulse) yielded the equation:

$$
\log \left(k / \mathrm{cm}^{3} \text { molecule } \mathrm{s}^{-1}\right)=(-10.37 \pm 0.17)+\left(0.36 \pm 1.12 \mathrm{~kJ} \mathrm{~mol}^{-1}\right) / R T \ln 10
$$

The error limits are based on the spread of each individual rate constant.

In addition to these experiments, some runs were carried out at other total pressures in the range 1 to 100 Torr $\left(\mathrm{SF}_{6}\right)$ at the higher laser pulse energy. These were generally single point 
determinations. The results are shown in Table 2. It was assumed that the uncertainties were $10 \%$, ie slightly greater than the standard deviations of the second order plots. Examination of the values shows that these is no discernable pressure dependence of the rate constants above 10 Torr at any temperature. Below 10 Torr, there is a slight fall off in values.

The dependence of $k_{\mathrm{obs}}$ on laser intensity was studied as a possible aid to unravelling the mechanism. In the practical range of study ( 25 to $120 \mathrm{~mJ} /$ pulse), the only detectable variation occurred between 30 and $60 \mathrm{~mJ} /$ pulse. These results are already shown in Table 1 . Above 60 $\mathrm{mJ} /$ pulse, values of $k_{\mathrm{obs}}$ (not shown) were rather scattered although not detectably larger in magnitude.

Ab Initio Calculations. Possible species of the $\mathrm{SiH}_{5} \mathrm{~N}$ family were explored in some detail at the G3 level of theory and are shown on the potential energy surface (PES) in Figure 3. A fairly straightforward surface and set of species has been found. This comprises three local minima (ie stable intermediates or products), apart from the reactants, $\mathrm{SiH}_{2}+\mathrm{NH}_{3}$, and three transition states. The lowest energy reaction pathway may be described as follows. The initial step forms the donor-acceptor complex (ylid), $\mathrm{H}_{2} \mathrm{Si} \cdot \cdot \mathrm{NH}_{3}$, which can then either undergo a nitrogen-to-silicon $\mathrm{H}$-shift via TS1 to form silylamine, $\mathrm{SiH}_{3} \mathrm{NH}_{2}$, or decompose via TS2 to give aminosilylene, $\mathrm{HSiNH}_{2}$, by $\mathrm{H}_{2}$ elimination (a 4-centre process). $\mathrm{HSiNH}_{2}$ can also be formed directly from $\mathrm{SiH}_{3} \mathrm{NH}_{2}$ by $\mathrm{H}_{2}$ elimination from silicon (a 3-centre process) via TS3. It should be noted that, to reach either $\mathrm{SiH}_{3} \mathrm{NH}_{2}$ or $\mathrm{HSiNH}_{2}$, the reactants have to overcome positive energy barriers. The structures of the intermediate species, products and reaction transition states are shown in Figure 4 and the enthalpy values are listed in Table 3. Further calculations of the energies of these species with larger basis sets showed small changes in values (listed in Table 3) but do not give rise to any different mechanistic expectations.

Additionally we have explored briefly a few species on the $\mathrm{SiH}_{4} \mathrm{~N}$ potential energy surface (G3 level only). These consist of the aminosilyl radical, $\mathrm{H}_{2} \mathrm{SiNH}_{2}$, and its possible decomposition 
products, $\mathrm{SiH}_{2}+\mathrm{NH}_{2}, \mathrm{HSiNH}_{2}+\mathrm{H}$ and $\mathrm{H}_{2} \mathrm{Si}=\mathrm{NH}+\mathrm{H}$. The enthalpy values for these are included in Table 3. It should be noted that starting from $\mathrm{SiH}_{2}+\mathrm{NH}_{2}$, all possible pathways are exothermic.

\section{Discussion}

Evaluation of the kinetics. The experimental objective of this study was to investigate the kinetics of reaction of silylene in the presence of ammonia, in the hope of obtaining absolute values of rate constants for the elementary reaction, $\mathrm{SiH}_{2}+\mathrm{NH}_{3}$. The first objective has been achieved, and the kinetic results have characteristics strongly resembling those of a typical $\mathrm{SiH}_{2}$ reaction. Second order kinetics has been established. The magnitude of the rate constants is quite high. There is only a very slight temperature dependence of the rate constants, with a negative activation energy. The Arrhenius parameters look reasonable. The measured value for $\log \left(A / \mathrm{cm}^{3}\right.$ molecule $\mathrm{s}^{-1}$ ) of -10.37 compares favourably with the range, -9.88 to -12.09 , found for other silylene reactions (see ref 14, Table 7 for the most recent values). The value for the activation energy of $-0.36 \pm 1.12 \mathrm{~kJ} \mathrm{~mol}^{-1}$ is close to the range, -1.6 to $-4.5 \mathrm{~kJ} \mathrm{~mol}^{-1}$, of most silylene reactions. There are however two features which tend to suggest that the kinetics are not those of the simple reaction, $\mathrm{SiH}_{2}+\mathrm{NH}_{3}$. The first is that of the lack of overall pressure dependence, except at low pressures. It is overwhelmingly likely that the true reaction of $\mathrm{SiH}_{2}$ with $\mathrm{NH}_{3}$ is an association process, in which case a pressure dependent reaction should be expected. This is discussed in more detail below. The second feature is that of the dependence of the rate constants on laser intensity. If the reaction of $\mathrm{SiH}_{2}$ is with substrate alone, there should be no such dependence. This was verified by us for the reaction $\mathrm{SiH}_{2}+\mathrm{Me}_{2} \mathrm{CO}^{9}$. If there are reactions of $\mathrm{SiH}_{2}$ with radicals or other intermediates, then intensity dependences of the apparent rate constants can arise. We found this in our study of $\mathrm{SiH}_{2}+\mathrm{CH}_{3} \mathrm{Cl}^{16}$. 
$\mathrm{Ab}$ initio calculations for $\mathrm{SiH}_{2}+\mathrm{NH}_{3}$ and further mechanistic considerations. The earlier theoretical calculations of Raghavachari et $\mathrm{al}^{4}$ revealed a donor acceptor adduct with a binding energy (well depth) of $105 \mathrm{~kJ} \mathrm{~mol}^{-1}$ and a barrier to rearrangement of $54 \mathrm{~kJ} \mathrm{~mol}^{-1}$ (above the reaction threshold). The results obtained here at the higher G3 level, are in reasonable accord with this, although the rearrangement barrier is slightly lower. The barrier is still high enough, however, to make surmounting it impossible under experimental conditions ${ }^{30}$. We have extended the earlier work, by the discovery of the $\mathrm{H}_{2}$ elimination pathway from the adduct leading directly to $\mathrm{HSiNH}_{2}$. However this also has a sufficiently high energy barrier to make it very unlikely that this process can occur here either. It is worth noting that $\mathrm{H}_{2}$ elimination pathways have also been found from the adducts of $\mathrm{SiH}_{2}$ with $\mathrm{H}_{2} \mathrm{O}^{5,6}$ and with $\mathrm{HCl}^{15}$, although only in the latter case is the step thought to be occurring under experimental conditions. This means that, unless there is a hitherto unidentified pathway, the effective final reaction product should be the adduct, $\mathrm{H}_{2} \mathrm{Si} \cdot \mathrm{NH}_{3}$. This is the situation found previously for the reaction system, $\mathrm{SiH}_{2}+\mathrm{H}_{2} \mathrm{O}$, where $\mathrm{H}_{2} \mathrm{Si} \cdot \cdot \mathrm{OH}_{2}$ was the final product ${ }^{6}$. Since $\mathrm{SiH}_{2}+\mathrm{NH}_{3} \rightarrow \mathrm{H}_{2} \mathrm{Si} \cdot \mathrm{NH}_{3}$ is an association process, the question arises as to what extent it should be pressure dependent, ie what is the magnitude of the third body effect at $298 \mathrm{~K}$ ? Although in principle this could be calculated using RRKM theory, there is sufficient literature information to make a reasonable estimate. The system under study here, lies between those of $\mathrm{SiH}_{2}+\mathrm{H}_{2} \mathrm{O}$ (well depth $\left.=54-65 \mathrm{~kJ} \mathrm{~mol}^{-1}\right)^{5,6}$ and $\mathrm{SiH}_{2}+\mathrm{C}_{2} \mathrm{H}_{4}$ (well depth $\left.=187 \mathrm{~kJ} \mathrm{~mol}^{-1}\right)^{31}$. The main determinant of the extent of pressure dependence is the binding energy, ie well depth, although molecular size also affects it. In the $\mathrm{SiH}_{2}+\mathrm{H}_{2} \mathrm{O}$ system, the rate constant in 10 Torr of $\mathrm{SF}_{6}\left(1.4 \times 10^{-12} \mathrm{~cm}^{3}\right.$ molecule $\left.\mathrm{s}^{-1}\right)$ is at least two orders of magnitude below the high pressure limiting value and the variation between 10 and 100 Torr is a factor of 3.6. In the $\mathrm{SiH}_{2}+\mathrm{C}_{2} \mathrm{H}_{4}$ system, the rate constant at 10 Torr of $\mathrm{SF}_{6}\left(1.58 \times 10^{-10} \mathrm{~cm}^{3}\right.$ molecule $\mathrm{s}^{-1}$ ) is a factor of 2.2 below the high pressure limiting value and the variation between 10 and 100 Torr is a factor of 1.8 (and a further factor of 2.3 between 1 and 10 Torr). The 
parameters of the $\mathrm{SiH}_{2}+\mathrm{NH}_{3}$ system are closer to those of $\mathrm{SiH}_{2}+\mathrm{H}_{2} \mathrm{O}$ than $\mathrm{SiH}_{2}+\mathrm{C}_{2} \mathrm{H}_{4}$ meaning that we would anticipate rate constants at least an order of magnitude below the high pressure limiting value and a variation with pressure of a factor of 2 to 3 between 10 and 100 Torr and larger than this between 1 and 10 torr. Although there is some uncertainty in these estimates, the observed pressure dependence at $299 \mathrm{~K}$ is almost nothing, ie nowhere near to this. It therefore seems very unlikely that we are observing the reaction $\mathrm{SiH}_{2}+\mathrm{NH}_{3}$. The true values for the second order rate constants of this reaction are almost certainly smaller than we are observing probably by as much as an order of magnitude (at 10 Torr). It is also probable that a catalysed process, involving two molecules of $\mathrm{NH}_{3}$, by analogy with findings in the $\mathrm{SiH}_{2}+\mathrm{H}_{2} \mathrm{O}$ reaction system ${ }^{32}$, would contribute to $\mathrm{SiH}_{2}$ removal. The non-observation of a quadratic dependence of $k_{\mathrm{obs}}$ on $\left[\mathrm{NH}_{3}\right]$ can therefore be taken as further evidence against the direct reaction of $\mathrm{SiH}_{2}$ with $\mathrm{NH}_{3}$.The nature of the removal process for $\mathrm{SiH}_{2}$ is discussed in the next section.

Radical reactions and the removal mechanism for $\mathrm{SiH}_{2}$. Photodecomposition of $\mathrm{NH}_{3}$ is likely to be the main cause of complexity in this study, viz.

$$
\mathrm{NH}_{3}+\mathrm{h} v \rightarrow \mathrm{NH}_{2}+\mathrm{H}
$$

At both 184.9 and $206.2 \mathrm{~nm}$ the quantum yield for this process is near unity ${ }^{21}$. It is almost certainly similar at $193 \mathrm{~nm}$. With a fairly high extinction coefficient at $193 \mathrm{~nm}$, this means that high instantaneous concentrations of $\mathrm{NH}_{2}$ radicals will be formed. Because of the high ratio of substrate to $\mathrm{SCP}$, instantaneous $\mathrm{NH}_{2}$ concentrations will be well in excess of those of $\mathrm{SiH}_{2}$ and could be as much as $10 \%$ of those of $\mathrm{NH}_{3}$ in the reaction zone. It is also worth noting that at high $\mathrm{NH}_{3}$ partial pressures (> 200 mTorr) there is a significant decrease in initial $\mathrm{SiH}_{2}$ signal intensity suggesting increased competition for the excitation pulse by the substrate. Thus it seems very probable that $\mathrm{SiH}_{2}$ is being removed by reaction with $\mathrm{NH}_{2}$, viz

$$
\mathrm{SiH}_{2}+\mathrm{NH}_{2} \rightarrow \mathrm{H}_{2} \mathrm{SiNH}_{2} * \rightarrow \mathrm{HSiNH}_{2}+\mathrm{H}
$$


Although nothing is known experimentally about this reaction, a reaction between silylene and a radical is expected to be barrierless (our calculations have shown that the species are spontaneously attracted from approach distances of $3 \AA$ ). The initially formed aminosilyl radical will have vibrational energy well in excess of that needed to decompose by $\mathrm{H}$ atom expulsion (see energetics of Table 3) and should form aminosilylene, $\mathrm{HSiNH}_{2}$, although formation of isomeric $\mathrm{H}_{2} \mathrm{Si}=\mathrm{NH}$ is also energetically possible. This is important because it means that reaction between $\mathrm{SiH}_{2}$ and $\mathrm{NH}_{2}$ will not be pressure dependent.

With $\left[\mathrm{NH}_{2}\right]$ in excess over $\left[\mathrm{SiH}_{2}\right]$, pseudo first order kinetics for $\mathrm{SiH}_{2}$ should be maintained, as observed. Although $\mathrm{NH}_{2}$ radical recombination might be expected to deplete initial $\mathrm{NH}_{2}$ concentrations, it is a pressure dependent association process ${ }^{21}$ and should not compete significantly. This may be the reason why the dependence of the rate constants on laser intensity is not very great. Normally one would expect radical-radical reactions to be more significant at high light intensities that at low light intensities. But if $\mathrm{NH}_{2}$ recombination is slow, $\left[\mathrm{NH}_{2}\right]$ may decrease rather slowly on the experimental time scale and it can maintain an approximate proportionality with $\left[\mathrm{NH}_{3}\right]$. Nevertheless some dependence on intensity, as observed, is a sign of reaction between two transient species. The greater than normal scatter in the data is also an indicator of more complex kinetics.

The fate of $\mathrm{H}$ atoms is another potential cause of complexity. Reaction of $\mathrm{H}$ with $\mathrm{NH}_{3}$ is very slow ${ }^{21}$, and so reaction of $\mathrm{H}$ with $\mathrm{SCP}$ seems probable. However this will only occur after formation of $\mathrm{SiH}_{2}$ and therefore not affect the kinetics. Even if SCP is largely consumed in the reaction zone as a consequence, it will be replenished by diffusion between shots (as shown by the test for depletion). 


\section{Conclusion}

Under the conditions of the present experiments, silylene is removed by reaction, not with $\mathrm{NH}_{3}$, but rather by $\mathrm{NH}_{2}$, formed by the $193 \mathrm{~nm}$ photodissociation of $\mathrm{NH}_{3}$. To study the elementary $\mathrm{SiH}_{2}+\mathrm{NH}_{3}$ reaction will require an $\mathrm{SiH}_{2}$ precursor whose decomposition occurs outside the $\mathrm{NH}_{3}$ absorption wavelength region (viz $170-220 \mathrm{~nm}$ ).

\section{Acknowledgement.}

R.B. and R.W. thank Dow-Corning for a grant in support of the experimental work. R.B. also thanks the Spanish DGI for support under project BQU2002-03381. We also thank Irina Krylova (Zelinsky Institute of Organic chemistry, Moscow) for preparation of the sample of silacyclopent-3-ene.

\section{References and Notes}

(1) Jasinski, J. M.; Becerra, R.; Walsh, R. Chem. Rev. 1995, 95, 1203.

(2) Becerra, R.; Walsh, R. Kinetics \& mechanisms of silylene reactions: A prototype for gasphase acid/base chemistry. In Research in Chemical Kinetics; Compton, R. G., Hancock, G., Eds.; Elsevier: Amsterdam, 1995; Vol. 3, p 263.

(3) Gaspar, P. P.; West, R. Silylenes. In The Chemistry of Organic Silicon Compounds; Rappoport, Z., Apeloig, Y., Eds.; Wiley: Chichester, 1998; Vol. 2, Chapter 43, p 2463.

(4) Raghavachari, K.; Chandrasekhar, J.; Gordon, M. S.; Dykema, K. J. J. Am. Chem. Soc. 1984, 106, 5853 .

(5) Alexander, U. N.; King, K. D.; Lawrance, W. D. J. Phys. Chem. A 2002, 106, 973.

(6) Becerra, R.; Cannady, J. P.; Walsh, R. J. Phys. Chem. A 2003, 107, 11049.

(7) Becerra, R.; Carpenter, I. W.; Gutsche, G. J.; King, K. D.; Lawrance, W. D.; Staker, W. S.; Walsh, R. Chem. Phys. Lett. 2001, 333, 83. 
(8) Alexander, U. N.; King, K. D.; Lawrance, W. D. Phys. Chem. Chem. Phys. 2001, 3, 3085.

(9) Becerra, R.; Cannady, J. P.; Walsh, R. J. Phys. Chem. A 1999, 103, 4457.

(10) Becerra, R.; Cannady, J. P.; Walsh, R. Phys. Chem. Chem. Phys. 2001, 3, 2343.

(11) Becerra, R.; Cannady, J. P.; Walsh, R. J. Phys. Chem. A 2002, 106, 11558.

(12) Becerra, R.; Cannady, J. P.; Walsh, R. J. Phys. Chem. A 2001, 105, 1897.

(13) Becerra, R.; Cannady, J. P.; Walsh, R. J. Phys. Chem. A 2002, 106, 4922.

(14) Becerra, R.; Bowes, S-J.; Ogden, J. S.; Cannady, J. P.; Adamovic, I.; Gordon, M.S; Almond, M. J.; Walsh, R. Phys. Chem. Chem. Phys. A 2005, 7, 2900.

(15) Becerra, R.; Cannady, J. P.; Walsh, R. J. Phys. Chem. A 2004, 108, 3987.

(16) Becerra, R.; Cannady, J. P.; Walsh, R. J. Phys. Chem. A 2006, 110, 6680.

(17) Becerra, R.; Frey, H. M.; Mason, B. P.; Walsh, R. Chem. Phys. Lett. 1991, 185, 415.

(18) Becerra, R.; Bowes, S-J.; Ogden, J. S.; Cannady, J. P.; Almond, M. J.; Walsh, R. J. Phys. Chem. A 2005, 109, 1071.

(19) Becerra, R.; Cannady, J. P.; Walsh, R. J. Phys. Chem. A 2003, 107, 9588.

(20) Lange, H.; Watting, G. Angew. Chem. Int. Edn, Engl. 1991, 30, 1579.

(21) Okabe, H. Photochemistry of Small Molecules, Wiley-Interscience, New York, 1978, pp. 269-272.

(22) Ando, W.; Sekiguchi, A.; Hagiwara, K.; Sakakibara, A.; Yoshida, H. Organometallics 1988, 7, 558 .

(23) Gillette, G. R.; Noren, G. H.; West, R. Organometallics 1989, 8, 487.

(24) Becerra, R.; Frey, H. M.; Mason, B. P.; Walsh, R.; Gordon, M. S. J. Chem. Soc., Faraday Trans. 1995, 91, 2723.

(25) Baggott, J. E.; Frey, H. M.; King, K. D.; Lightfoot, P. D.; Walsh, R.; Watts, I. M. J. Phys. Chem. 1988, 92, 4025.

(26) Jasinski, J. M.; Chu, J. O. J. Chem. Phys. 1988, 88, 1678.

(27) Frisch, M. J.; Trucks, G. W.; Schlegel, H. B.; Scuseria, G. E.; Robb, M. A.; Cheeseman, J. R.; Zakrzewski, V. G.; Montgomery, Jr., J. A.; Stratmann, R. E.; Burant, J. C.; Dapprich, 
S.; Millam, J. M.; Daniels, A. D.; Kudin, K. N.; Strain, M. C.; Farkas, O.; Tomasi, J.; Barone, V.; Cossi, M.; Cammi, R.; B. Mennucci, B.; Pomelli, C.; Adamo, C.; Clifford, S.; Ochterski, J.; Petersson, G. A.; Ayala, P. Y.; Cui, Q.; Morokuma, K.; Malick, D. K.; Rabuck, A. D.; Raghavachari, K.; Foresman, J. B.; Cioslowski, J.; Ortiz, J. V.; Baboul, A. G.; Stefanov, B. B.; Liu, G.; Liashenko, A.; Piskorz, P.; Komaromi, R.; Gomperts, R.; Martin, R. L.; Fox, D. J.; Keith, T.; Al-Laham, M. A.; Peng, C. Y.; Nanayakkara, A.; Gonzales, C.; Challacombe, M.; Gill, P. M. W.; Johnson, B. G.; Chen, W.; Wong, M. W.; Andres, J. L.; Head-Gordon, M.; Replogle, E. S.; Pople, J. A. Gaussian 98, Revision A.9; Gaussian Inc.: Pittsburgh, PA, 1998.

(28) Curtiss, L. A.; Raghavachari, K.; Redfern, P. C.; Rassolov, V.; Pople, J. A. J. Chem. Phys. 1998, $109,7764$.

(29) Gonzales, C.; Schlegel, H. B. J. Chem. Phys. 1989, 90, 2154.

(30) The highest secondary barrier found to be surmountable under these experimental conditions is $c a 16 \mathrm{~kJ} \mathrm{~mol}^{-113}$.

(31) Al-Rubaiey, N.; Walsh, R. J. Phys. Chem. A, 1994, 98, 5303.

(32) Becerra, R.; Goldberg, N.; Cannady, J. P.; Almond, M. J.; Ogden, J. S.; Walsh, R. J. Am. Chem. Soc. 2004, 126, 6816. 
Table 1. Experimental second-order rate constants for the $\mathrm{SiH}_{2}+\mathrm{NH}_{3}$ system at three temperatures and two laser pulse energies.

\begin{tabular}{ccc}
\hline$T / \mathrm{K}$ & $k^{\mathrm{a}}(60 \mathrm{~mJ} /$ pulse $)$ & $k^{\mathrm{a}}(30 \mathrm{~mJ} /$ pulse $)$ \\
\hline 299 & $4.78 \pm 0.25$ & $3.87 \pm 0.22$ \\
340 & $5.06 \pm 0.45$ & $4.09 \pm 0.49$ \\
400 & $4.62 \pm 0.43$ & $3.21 \pm 0.60$ \\
\hline
\end{tabular}

${ }^{\mathrm{a}}$ Units: $10^{-11} \mathrm{~cm}^{3}$ molecule ${ }^{-1} \mathrm{~s}^{-1}$

Table 2. Pressure dependence of experimental second-order rate constants for the $\mathrm{SiH}_{2}+\mathrm{NH}_{3}$ system at three temperatures (laser pulse energy: $60 \mathrm{~mJ}$ )

\begin{tabular}{ccc}
\hline$T / \mathrm{K}$ & $P\left(\mathrm{SF}_{6}\right) /$ Torr & $k / 10^{-11} \mathrm{~cm}^{3}$ molecule $\mathrm{s}^{-1}$ \\
\hline 299 & 1.2 & $3.47 \pm 0.35$ \\
& 3.0 & $4.30 \pm 0.43$ \\
& 10.0 & $4.78 \pm 0.25$ \\
& 30.2 & $4.70 \pm 0.47$ \\
& 100.4 & $4.67 \pm 0.47$ \\
340 & 1.2 & $3.07 \pm 0.31$ \\
& 3.5 & $4.36 \pm 0.44$ \\
& 10.0 & $5.06 \pm 0.45$ \\
& 30.7 & $4.43 \pm 0.44$ \\
400 & 73.0 & $4.73 \pm 0.47$ \\
& 10.0 & $4.62 \pm 0.45$ \\
& 30.8 & $4.49 \pm 0.45$ \\
& 101.8 & $4.90 \pm 0.49$ \\
\hline
\end{tabular}


Table 3. Ab Initio enthalpies for $\mathrm{SiH}_{5} \mathrm{~N}$ species of interest in the reaction of $\mathrm{SiH}_{2}$ with $\mathrm{NH}_{3}$ and also $\mathrm{SiH}_{4} \mathrm{~N}$ species of interest in the reaction of $\mathrm{SiH}_{2}$ with $\mathrm{NH}_{2}$

\begin{tabular}{|c|c|c|c|c|}
\hline \multirow{2}{*}{ Molecular species } & \multirow{2}{*}{ Energy/hartree(G3) } & \multicolumn{3}{|c|}{ Relative energy $/ \mathrm{kJ} \mathrm{mol}^{-1}$} \\
\hline & & G3 & $\mathrm{MP} 2 \mathrm{P}^{a}$ & $\mathrm{MP}^{2} \mathrm{DP}^{b}$ \\
\hline $\mathrm{SiH}_{2}+\mathrm{NH}_{3}$ & -346.956923 & 0 & 0 & 0 \\
\hline $\mathrm{H}_{2} \mathrm{Si} \cdot \cdot \mathrm{NH}_{3}$ ylid & -346.997317 & -106 & -121 & -104 \\
\hline TS1 & -346.943760 & 35 & 34 & 38 \\
\hline TS2 & -346.949134 & 20 & 25 & 25 \\
\hline $\mathrm{H}_{3} \mathrm{SiNH}_{2}$ & -347.058969 & -267 & -277 & -272 \\
\hline TS3 & -346.962400 & -14 & 4 & -4 \\
\hline $\mathrm{H}_{2}+\mathrm{HSiNH}_{2}$ & -347.001548 & -117 & -128 & -115 \\
\hline $\mathrm{SiH}_{2}+\mathrm{NH}_{2}$ & -346.288122 & 0 & - & - \\
\hline $\mathrm{H}_{2} \mathrm{SiNH}_{2}$ & -346.415466 & -334 & - & - \\
\hline $\mathrm{HSiNH}_{2}+\mathrm{H}$ & -346.336123 & -126 & - & - \\
\hline $\mathrm{H}_{2} \mathrm{Si}=\mathrm{NH}+\mathrm{H}$ & -346.311997 & -63 & - & - \\
\hline
\end{tabular}




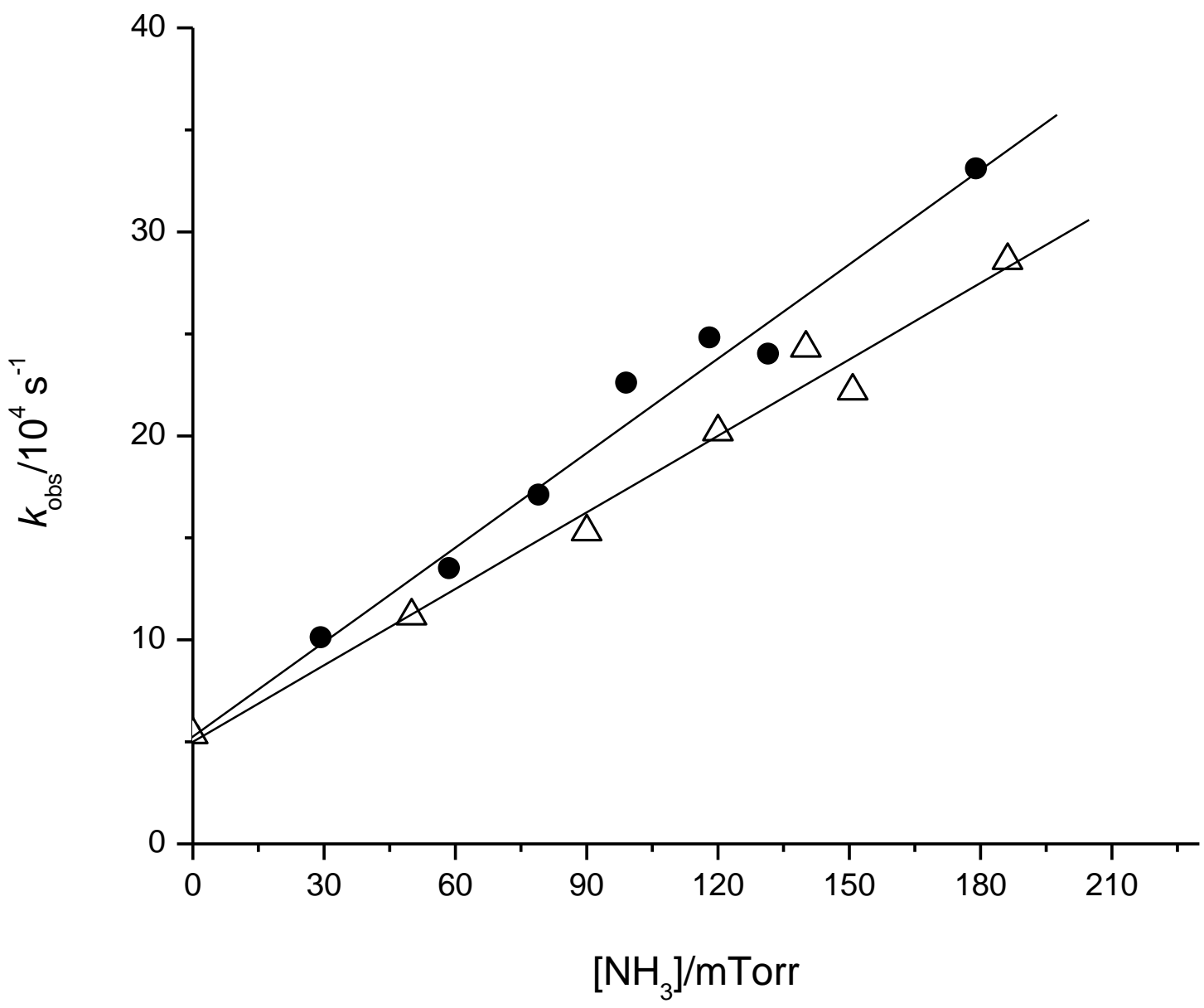

Figure 1. Second-order plot for reaction of $\mathrm{SiH}_{2}$ with $\mathrm{NH}_{3}$ at 10 Torr total pressure $\left(\mathrm{SF}_{6}\right)$ and 299 K. Laser pulse energies: $\bullet, 60 \mathrm{~mJ} ; \triangle, 30 \mathrm{~mJ}$. 


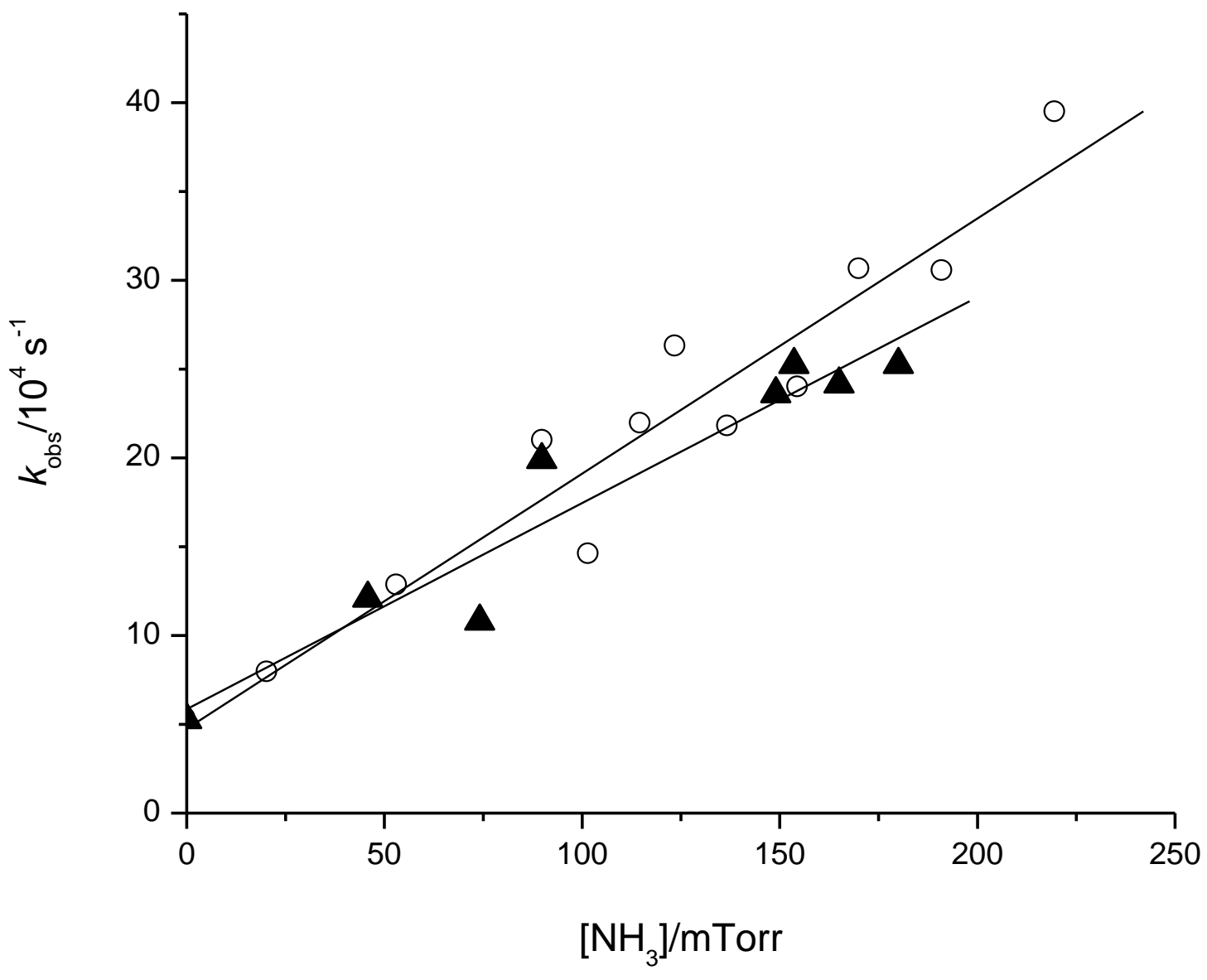

Figure 2. Second-order plot for reaction of $\mathrm{SiH}_{2}$ with $\mathrm{NH}_{3}$ at 10 Torr total pressure $\left(\mathrm{SF}_{6}\right)$ and 340 K. Laser pulse energies: O, $60 \mathrm{~mJ}$; $\mathbf{\Delta}, 30 \mathrm{~mJ}$. 


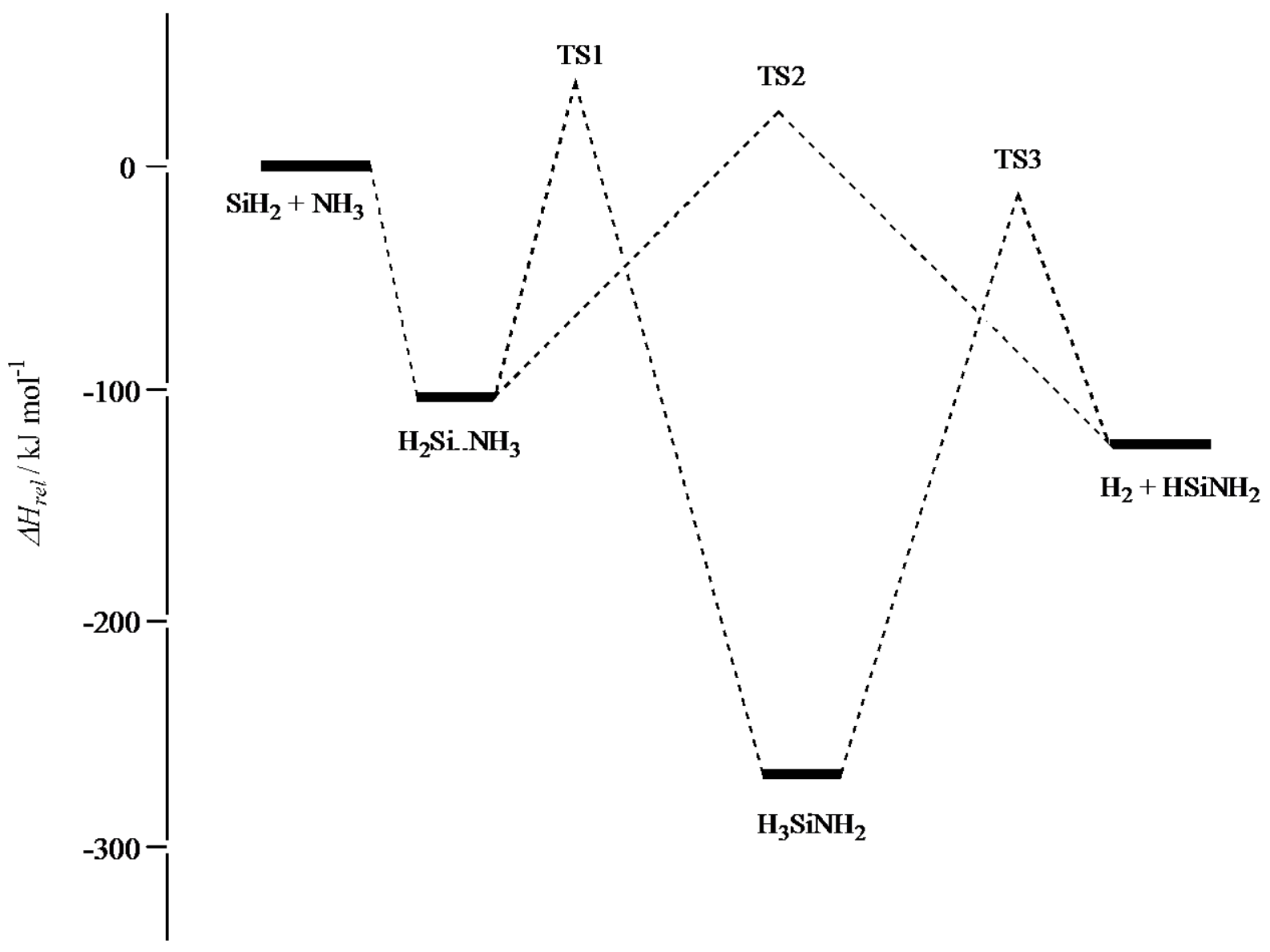

Figure 3. Potential energy (enthalpy) surface for the reaction of $\mathrm{SiH}_{2}+\mathrm{NH}_{3}$. All enthalpies are calculated at the G3 level. 


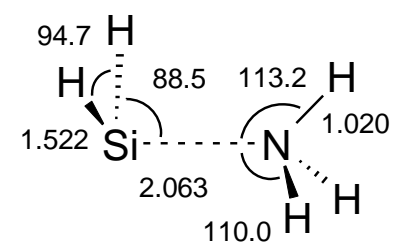

$\mathrm{H}_{2} \mathrm{Si} . . \mathrm{NH}_{3}$

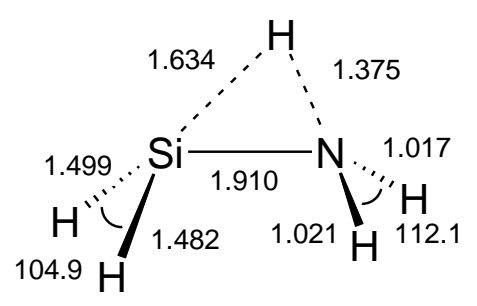

TS1

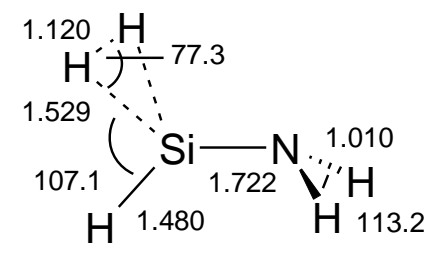

TS3

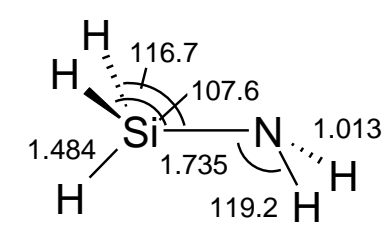

\section{$\mathrm{H}_{3} \mathrm{SiNH}_{2}$}

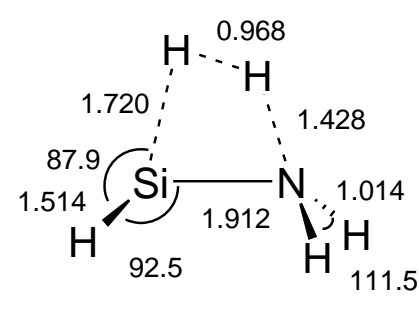

TS2

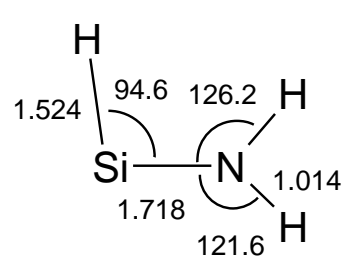

$\mathrm{HSiNH}_{2}$

Figure 4. Ab initio MP2 = full/6-31G(d) calculated geometries of local minimum structures and transition states on the $\mathrm{SiH}_{2}+\mathrm{NH}_{3}$ energy surface. Selected distances are given in $\AA$ and angles in degrees. 